\title{
EXPERIMENTAL AND NUMERICAL MODELING OF TSUNAMI LOADING ON STRUCTURES
}

\author{
Ioan Nistor ${ }^{1}$, Dan Palermo ${ }^{2}$, Andrew Cornett ${ }^{3}$, and Taofiq Al-Faesly ${ }^{4}$
}

\begin{abstract}
The results of a comprehensive research program on tsunami-induced forces on infrastructure located in coastal areas are presented. This research project is the result of an extensive interdisciplinary project (coastal and structural engineering) which spanned over the past five years and which included several field data reconnaissance missions, as well as analytical, experimental and numerical modeling of the extreme hydrodynamic forces on buildings and their component structural elements. The purpose of this research and engineering project is to elucidate the complex hydrodynamic mechanisms of the impact and extreme loadings on buildings and to properly quantify loads and further propose and derive new formulations for the design of structures located in the vicinity of the shoreline in tsunami-prone coastal areas.
\end{abstract}

Keywords: tsunami; coastal inundation; extreme hydrodynamic forces; tsunami loading; numerical modeling; SPH (Smooth Particle Hydrodynamics) Method

\section{BACKGROUND}

Tsunami waves are catastrophic events which can significantly impact communities located in many coastal areas around the world. In spite of their rare occurrence when compared to storm-induced surges or hurricanes, tsunami-induced coastal flooding often leads to extensive casualties and tremendous economic losses (Yeh 1991, Ghobarah et al. 2005, and Nistor et al. 2006).

The devastating effects of the 26 December 2004 Tsunami on countries bordering the Indian Ocean raised public awareness and indicated that existing design codes are not properly accounting for the tremendous forces and impacts generated by tsunamis. Prior to the 2004 Indian Ocean Tsunami, the design of structures against tsunami-induced forces was considered of minor importance when compared to the attention given to the tsunami warning systems. At the same time, other similar recent events such as the April 2007 Salmon Island Tsunami and the February 2010 Chile Tsunami have demonstrated that the extent of the damage and of the loss of human life can affect entire nations.

Reconnaissance missions of the December 2004 Indian Ocean Tsunami disaster revealed that tsunami-induced forces can lead to severe damage or collapse of structures (Ghobarah et al. 2005, Nistor et al. 2005, Saatcioglu et al. 2006, Tomita et al. 2006, and Yamamoto et al. 2006). It was found that it is imperative that these forces are properly accounted for in the design of infrastructure built within a certain distance from the shoreline in tsunami-prone areas. This highlighted the fact that current structural design codes do not account for tsunami-induced forces and the impact of associated debris. Reinforced concrete structures have been observed to withstand tsunamis with acceptable low levels of damage. However, at present, tsunami-induced forces and the impact of debris are still not properly quantified and accounted for in existing codes and significant improvement is needed. Moreover, significant disagreement on existing empirical formulas fostered new research interest in an effort to properly address the inclusion of both tsunami-induced forces and the impact of debris into design codes.

\section{TSUNAMI RESEARCH PROGRAM}

The paper provides results of a comprehensive interdisciplinary research project initiated at the University of Ottawa, Canada, which deals with the tsunami risk for coastal infrastructure. This interdisciplinary project has two components: (1): Identification and mapping of the Canadian coastal regions prone to the tsunami flood risk and development of tsunami inundation maps that can provide inundation depths and flow velocities for a given return period, and (2): Estimation of the tsunami impact on coastal infrastructure and the elaboration of design recommendations and guidelines for including tsunami loading into the National Building Code of Canada (NBCC). The members of the

${ }^{1}$ Associate Professor, Department of Civil Engineering, University of Ottawa, 161 Louis Pasteur CBY A106, Ottawa, ON, K1N 6N5, Canada, E-mail: inistor@uottawa.ca

${ }^{2}$ Assistant Professor, Department of Civil Engineering, University of Ottawa, 161 Louis Pasteur CBY A106, Ottawa, ON, K1N 6N5, Canada

${ }^{3}$ Group Leader, Hydrotechnical Engineering, NRC Canadian Hydraulics Centre, and Adjunct Professor, Department of Civil Engineering, University of Ottawa, 1200 Montreal Road, Building M32, Ottawa, ON, K1A OR6, Canada

${ }^{4} \mathrm{PhD}$ student, Department of Civil Engineering, University of Ottawa, 161 Louis Pasteur CBY A106, Ottawa, ON, K1N 6N5, Canada 
project include coastal engineers (Dr. Ioan Nistor and Dr. Andrew Cornett), tsunami scientists (Dr. Tad Murty), as well as structural engineers (Dr. Dan Palermo and Dr. Murat Saatcioglu).

Project (1) mentioned above deals with the tsunami risk for Canada, the country with the longest coastline in the world. Over the past several hundreds of years, several major tsunamis occurred along the eastern and particularly the western Canadian coastline. Hence, Project (1) focused on the numerical modeling of a massive tsunami generated by tectonic activity along the region of the Cascadia Fault, offshore British Columbia. The potential for inundation of the low-lying areas around the coastline of Vancouver Island and in and around the City of Vancouver was evaluated. At the same time, the authors collaborated with researchers from York University, Canada, in preparing the Tsunami Atlas for the Atlantic Ocean (Nirupama et al. 2007)

The preparation of design guidelines directly addressing tsunami-induced loading is intrinsically related to the correct estimation of hydrodynamic forces exerted on structures during a tsunami event. To address this issue, Project (2) of this research program was initiated by researchers in the Department of Civil Engineering of the University of Ottawa, Canada, in collaboration with the Canadian Hydraulics Center (CHC) of the National Research Council located in Ottawa, Canada. This research project focuses on the experimental, analytical, and numerical modeling of the hydrodynamic impacts on infrastructure and is coordinated by both coastal and structural engineers. The first stage of the experimental program (Palermo et al. 2009 and Nouri et al. 2010) has been finalized and some results of this work are presented herein. At present, a large-scale experimental test program and numerical modeling work are under way. The authors also contributed to the Handbook of Coastal and Ocean Engineering with the chapter on Tsunami Forces on Structures (Nistor et al. 2009).

The present paper presents an overview of some of the results obtained in the second component of the research program, pertaining to the experimental and numerical modelling of the tsunami-induced forces on infrastructure. Some brief details of the tsunami field surveys carried out by the authors are also presented.

\section{TSUNAMI FIELD INVESTIGATIONS}

The true scale of the impact and destruction brought by the tsunami waves on infrastructure and the communities located in coastal areas can only be grasped and understood in its real dimension by participating in post-tsunami disaster reconnaissance missions. The authors, from the University of Ottawa, in collaboration with researchers from McMaster University (Canada) and Yokohama National University (Jun Sasaki) and Waseda University (Tomoya Shibayama), carried out several field investigations in the regions affected by tsunami. Field investigations were carried out first in Thailand and Indonesia immediately following the December 2004 Indian Ocean Tsunami (January 2005), and the central coast of Chile (March 2010). Post-tsunami field surveys were also conducted to assess the effectiveness of the reconstruction efforts and further investigate other damage induced by the tsunami waves to the coastal areas around the Indian Ocean. Post-disaster field investigations included Thailand (2005), Sri Lanka (2006), and Tanzania (2007), and focused on reconstruction of infrastructure, hazard mitigation in the inundation-prone areas, as well as on the investigation of the long-term impact of tsunami attack on coastal morphodynamics and local communities.

The first tsunami field reconnaissance survey to Thailand and Indonesia was carried out in January 2005 by a team of three researchers from the University of Ottawa (Ioan Nistor and Murat Saatcioglu) and McMaster University (Ahmed Ghobarah). The visit focused on both urban and rural areas fitted often with either engineered or non-engineered structures, closest to the earthquake epicenter for the case of Indonesia.

Rawai Beach, Kata Noi Beach, Kata Beach, Patong Beach, Nai Thon Beach and Kamala Beach on the island of Phuket (Thailand) were visited first, followed by Phi-Phi Island, about $48 \mathrm{~km}$ south east of Phuket Island, as well as the coastal town of Khao Lak located about $100 \mathrm{~km}$ north of Phuket. The second stage of the tsunami survey was in Indonesia: Banda Aceh, the capital of Indonesia's Aceh Province located at the northern tip of Sumatra. The region and City of Banda Aceh suffered extensive tsunami damage and was, in fact, the coastal city most affected by tsunami anywhere around the Indian Ocean Basin. Moreover, due to its proximity to the earthquake epicenter, Banda Aceh region suffered also extensive seismic damage which was also surveyed and documented (Ghobarah et al. 2006).

Infrastructure damage was significant along the western coast of Thailand, as shown in Figures 1 and 2. Both engineered and non-engineering structures were seriously damaged by the force of the tsunami-induced coastal inundation. 


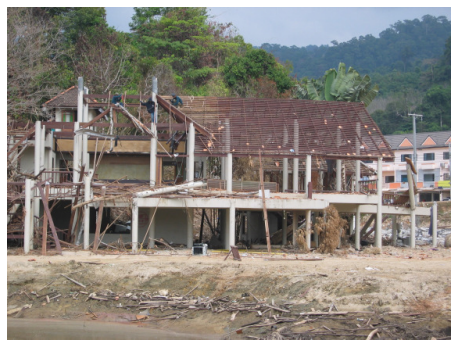

(a)

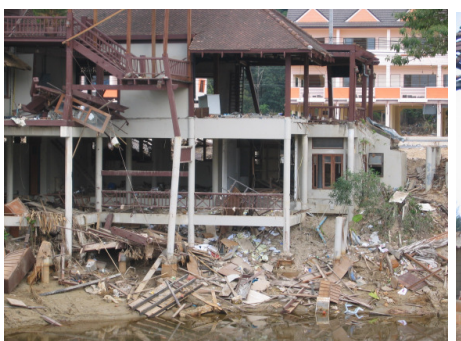

(b)

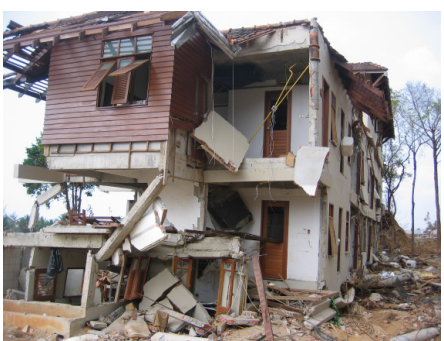

(c)

Figure 1. Structural damage in Nai Thon Beach, Thailand, due to tsunami waves

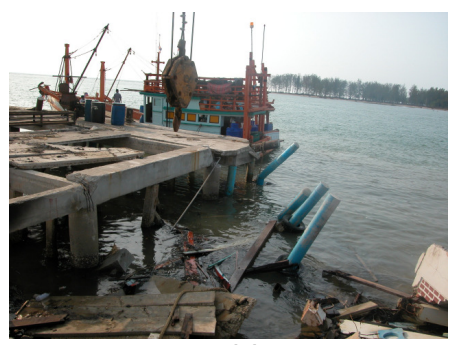

(a)

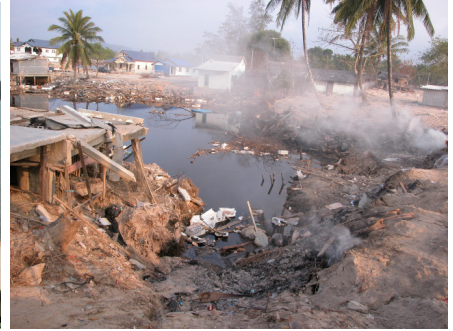

(b)

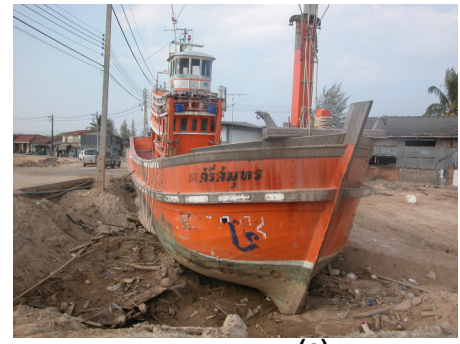

(c)

Figure 2. Tsunami-induced damage to the Khao Lak Port, Thailand

For the second leg of this field reconnaissance mission was conducted in Banda Aceh (Indonesia) and its surroundings, it was observed that a large number of non-engineered reinforced concrete buildings suffered structural damage. It was estimated that the city lost more than half of its population as a result of the extensive tsunami flooding. The measurements of the flooding extent indicated that the flood reached several kilometers inland. Most of the coastal structures in the region of Banda Aceh (the fishing ports, the commercial port, the protection dikes, etc) were completely wiped out (Saatcioglu et al. 2006). Figure 3 illustrates the extent of damage observed in Banda Aceh caused by both the earthquake and the ensuing tsunami flooding.

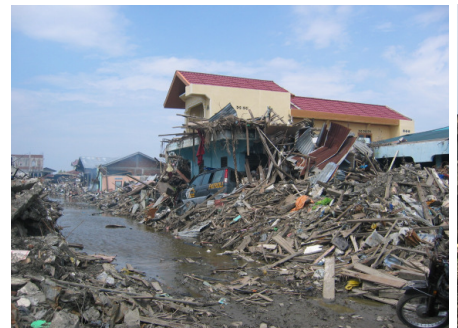

(a)

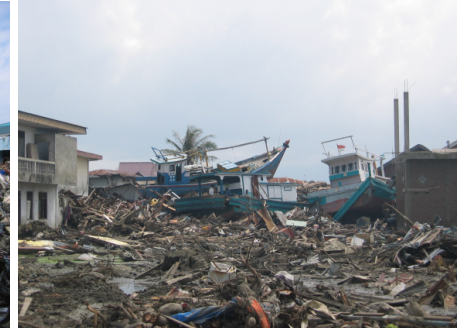

(b)

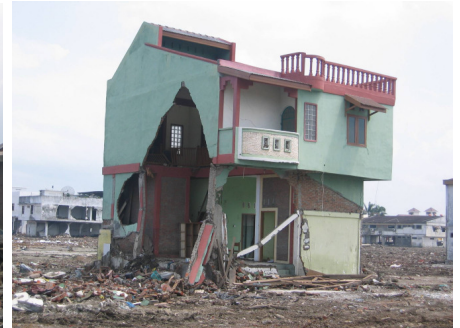

(c)

Figure 3. Tsunami damage in Banda Aceh, Indonesia, 2004 Indian Ocean Tsunami

Another tsunami field survey was conducted in March 2010 along the central coastline of Chile, following the earthquake and tsunami by a multidisciplinary Canadian research team. The team was composed of several researchers and consulting engineers who investigated damage caused by both the earthquake and the ensuing tsunami. Two of the authors (Ioan Nistor and Dan Palermo) have surveyed the damage produced by tsunami along a swath of the Chilean coastline stretching from Concepcion (Talcahuano) in the south to Pichilemu in the north. Several communities significantly impacted by tsunami waves were surveyed (Conception, Talcahuano, Dichato, Pelluhue and Constitution) and field measurements focused on the impact of the extreme hydrodynamic forces and coastal inundation on the exposed infrastructure: buildings, houses, bridges, lifelines, etc. In spite of similar patterns of infrastructure damage generated by tsunami, unlike the case of the 2004 Indian Ocean Tsunami, the loss of human lives was much reduced. The interviews conducted with the local inhabitants in Talcahuano, Pelluhue, Dichato, and Constitution showed that most of them were able to take refuge to higher ground immediately after they felt the earthquake, in spite of the fact that the tsunami warning system has not 
properly functioned. Figure 4 shows some of the infrastructure damage that the authors recorded during the March 2010 tsunami field survey in Chile.

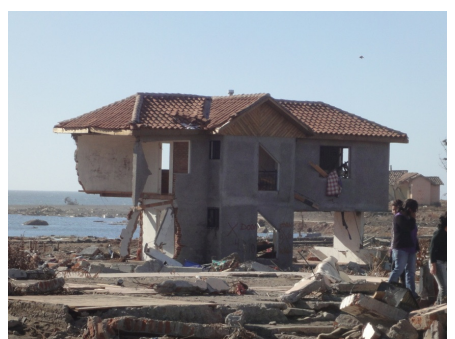

(a)

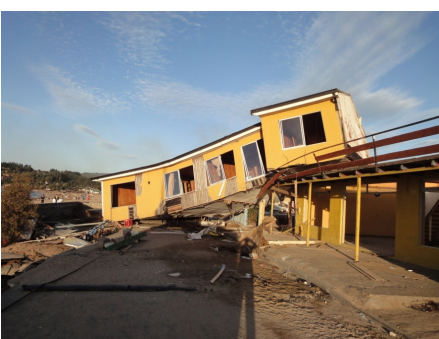

(b)

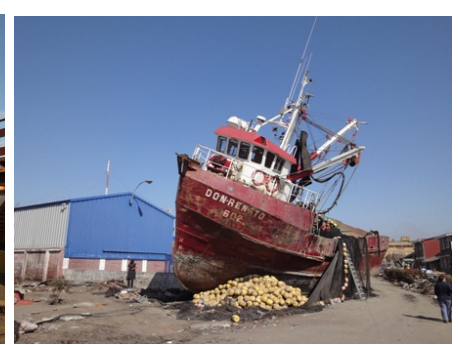

(c)

Figure 4. Tsunami infrastructure damage due to the 2010 Chile Earthquake and Tsunami

Follow-up tsunami field investigations conducted in Thailand (November 2005), Sri Lanka (October 2006), and Tanzania (October 2007), and showed that the infrastructure reconstruction efforts in the three visited countries outlined several common problems:

1.Though construction zoning for tsunami-prone coastal areas has been either proposed (Thailand and Tanzania) or legislated (Sri Lanka), the development of coastal infrastructure continued to appear chaotic and simply ignores the new provisions;

2.For the vast majority of the structures surveyed in these countries, the redesign and reconstruction of the coastal infrastructure was undertaken without accounting for or even making any provisions for tsunami loading.

\section{TSUNAMI-INDUCED LOADING RESEARCH AND EXISTING GUIDLINES}

Coastal regions have experienced intense development and must hence satisfy various economic needs, from harbours and port development, to the numerous tourists and investors who are constantly seeking new resort locations. This has lead to the construction of significant structures along coast lines; many are lying within inundation zones for tsunami flood waters. Such structures, used predominantly for residential purposes, are generally designed for earthquake loading, if located in seismic zones, and wind loading. However, as witnessed during the 2004 Indian Ocean Tsunami, near-shoreline structures suffered extensive damage due to the loading imposed by the tsunami-generated waves. This has raised globally awareness, and engineers and building owners are beginning to question whether their structures can withstand a similar tsunami event. Design documents or building codes that specifically address tsunami loading on near-shoreline structures are lacking, and existing documents, such as FEMA 55, were developed primarily for coastal structures and only one of the newer design guidelines which specifically address tsunami loading, FEMA 646, has been produced. However, some of the elements that enter the calculation of the tsunami-induced forces, such as flow velocity, duration of impact of floating debris, hydrodynamic pressure diagrams, and the response of the structure as a function of its structural characteristics have yet to be properly measured and quantified.

The preparation of design guidelines directly addressing tsunami-induced loading is intrinsically related to the correct estimation of hydrodynamic forces exerted on structures during a tsunami event. Five design documents specifically account for tsunami-induced forces, namely: the Federal Emergency Management Agency Coastal Construction Manual, FEMA 55 (FEMA 2003); the City and County of Honolulu Building Code (CCH 2000); the Structural Design Method of Buildings for Tsunami Resistance (SMBTR) proposed by the Building Center of Japan (Okada et al. 2005); Guidelines for Structures that Serve as Tsunami Vertical Evacuation Sites, prepared by Yeh et al. (2005) for the Washington State Department of Natural Resources to estimate tsunami-induced forces on structures. Recently, the Federal Emergency Management Agency published Guidelines for Design of Structures for Vertical Evacuation from Tsunamis, FEMA P646, (FEMA, 2008) which suggests eight different force components that should be included in tsunami load estimation. The purpose of FEMA P646 is to provide design requirements for tsunami refuge building which could withstand tsunami events while the regular-use buildings are to be designed with loads which allow for minor non-structural damage. However, there are significant differences in the provisions of all these design codes. Moreover, some of them (FEMA 55) do not really account for tsunami loading or, certain parameters, such as the bore velocity, debris impact characteristics, are quite differently estimated from code to code and hence need to be properly investigated. 
This ongoing interdisciplinary research program at the University of Ottawa, Canada, focuses on the experimental, analytical and numerical modeling of the hydrodynamic impacts on infrastructure and is developed in cooperation by both hydraulic/coastal engineers and structural engineers.

\section{TSUNAMI FORCES ON STRUCTURES - EXPERIMENTAL WORK}

A tsunami wave running inland generates forces which can significantly affect structures located in its path. Three parameters are essential for defining the magnitude and application of these forces: (1) inundation depth, (2) flow velocity, and (3) flow direction. The parameters mainly depend on: (a) tsunami wave height and wave period; (b) coast topography; and (c) roughness of the coastal inland. The extent of tsunami-induced coastal flooding, and therefore the inundation depth at a specific location, can be estimated using various tsunami scenarios (magnitude and direction) and modeling coastal inundation accordingly. However, the estimation of flow velocity and direction is generally more difficult. Flow velocities can vary in magnitude from zero to significantly high values, while flow direction can also vary due to onshore local topographic features, as well as soil cover and obstacles. Broken tsunami waves often inundate the shoreline in the form of a hydraulic bore, which is a fast advancing body of water with an abrupt front. However, while the impact of tsunami-induced forces on coastal protection structures, such as breakwaters, seawalls, etc, has been analyzed and, to a certain degree, clarified by researchers and engineers, the mechanisms of impingement of broken tsunami waves on structures located inland are not yet well understood. No structural engineering design codes explicitly consider tsunami loading, as it is understood that inland infrastructure can be protected by proper construction zoning and site planning. Therefore, forces generated by tsunami are rarely accounted for in structural design practice. Recent catastrophic events (2004 Indian Ocean Tsunami; 2007, 2009 Solomon Islands Tsunamis, 2010 Chile Tsunami) have, once more, stressed the importance of protecting structures located in areas with potential risk of being affected by the destructive power of tsunami-induced hydraulic bores.

The force components suggested by Nistor et al. (2009), FEMA 55, CCH, and FEMA 646 were investigated by the authors in collaboration with the Canadian Hydraulics Centre of the National Research Council in Ottawa, Canada. The experimental program consisted of physical simulations of hydraulic bores impacting structural components. The testing was carried out in a high discharge flume measuring $10.0 \mathrm{~m}$ in length, $2.7 \mathrm{~m}$ in width, and $1.4 \mathrm{~m}$ in height. Figure 5 is a schematic of the testing facility.

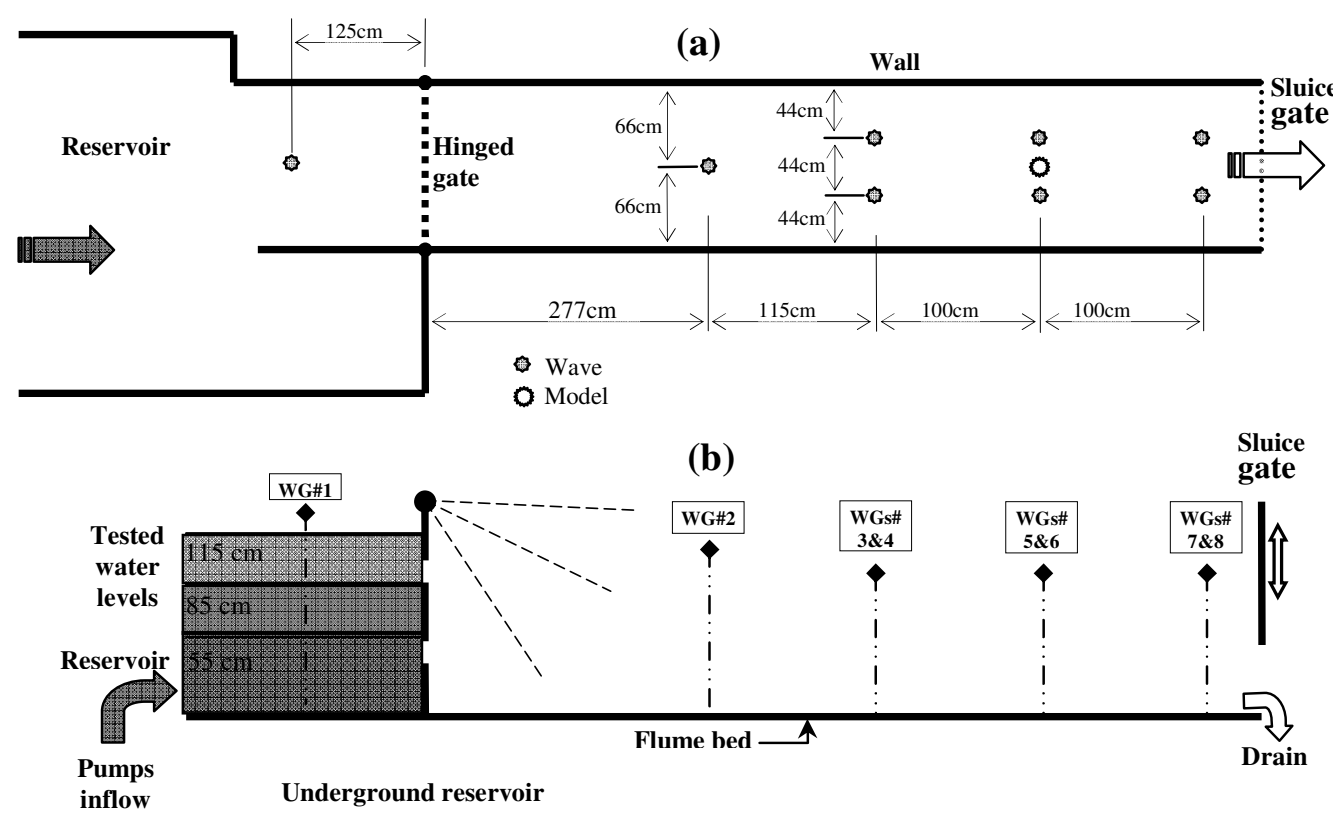

Not to scale

Figure 5. Experimental setup: a) plan view; b) side view. 
For this experimental program, the flume was partitioned to create a testing zone $1.3 \mathrm{~m}$ wide and $7.3 \mathrm{~m}$ long (Nouri et al. 2010). A hinged gate was designed and installed near the upstream section of the flume. In the closed position, the gate could impound a specified depth of water (impoundment depth). The hinging mechanism of the gate permitted a rapid opening ( 0.25 to 0.30 seconds), allowing the rapid separation of the impounded water from the hinged gate and the subsequent generation of a turbulent hydraulic bore which propagated through the flume and impacted the structural elements.

Significant efforts were directed towards the experimental investigation of the mechanisms of tsunami bore runup (Yeh and Mok 1990, Yeh 1991, Yeh et al. 2005). Although a two-dimensional dambreak phenomenon was used in the experiments, the bore motion was observed to be fully threedimensional and highly turbulent. This is in agreement with other observations regarding the irregularity of the bore front in transverse direction and the noticeable fluctuation of the front propagation (Yeh and Mok 1990).

The onshore propagation of the tsunami wave is similar to the classical dam-break problem. Chanson (2005 and 2006) compared the instantaneous free surface flow profiles of a tsunami-induced bore with floating bodies to a dam-break flow on a horizontal bed. A frame-by-frame analysis of a video recording taken during the Indian Ocean Tsunami in Banda Aceh, Indonesia was used to obtain the flow profile of the tsunami-induced bore. The agreement between the tsunami field data and the dam-break analytical formulation demonstrated the analogy between propagation of tsunami-induced bores and dam-break flow.

This study used two models of structural elements in the form of a square and round column. The square model was constructed of Plexiglas sheets ( 0.25 inches thickness), while the circular model was made of polyvinyl chloride (PVC) tube, with an outer diameter of $0.32 \mathrm{~m}$, thickness of $9 \mathrm{~mm}$ and height of $0.7 \mathrm{~m}$. Forces and pressures were measured on the two structures using pressure transducers and a six degrees of freedom load cell on which both structures were installed.

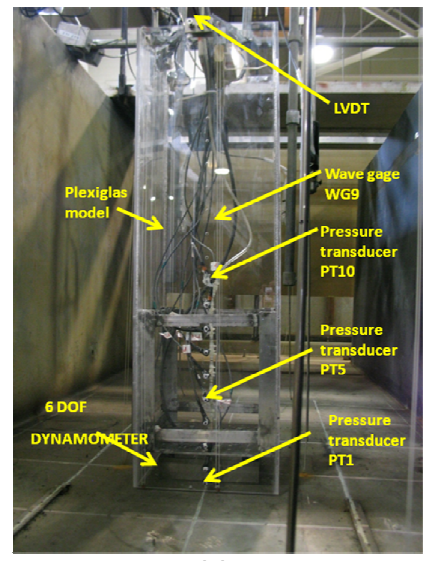

(a)

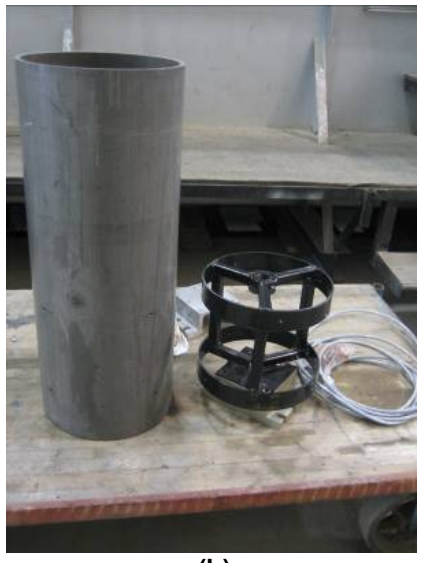

(b)

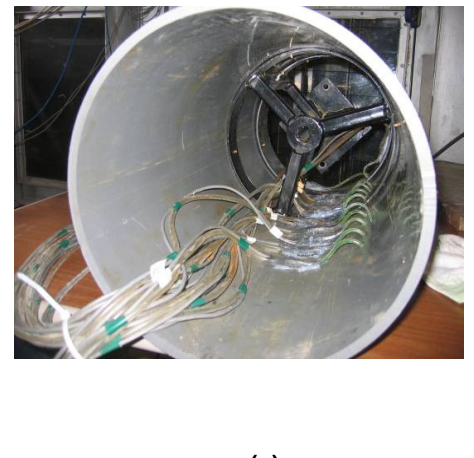

(c)

Figure 6. Structural elements and instrumentation: a) square column; b) and c) circular column.

The circular structure was connected to the upper surface of a six-axis dynamometer which was used to determine the base shear forces and the moments generated by the impacting hydraulic bore in the direction of the flow and transversally. In addition, nine pressure transducers were placed along a vertical line, flush with the surface, on the circular structure, directly facing the incoming bore. This ensured the recording of the time-history pressure profiles of the loading generated by the bore. The square structure, also shown in Figure 6 and 7, was instrumented with ten differential pressure transducers and five wave gages located at $5 \mathrm{~mm}$ from the sides structure (two on the side facing the bore, and one each for the lateral sides and two the back of the column), which recorded the timehistory of the water level around the structure. Three ADVs were initially deployed to measure the flow velocities but their functioning was not satisfactory due to intense cavitation around the head of the ADV. A high speed camera was used to measure flow velocities (work on the analysis is under way). There was approximately a 4-5mm gap beneath the lower base of the Plexiglas square column and the flume bed which was a construction requirement for attaching the structure to a six degree of freedom load cell. The gap was filled with flexible silicon glue to prevent water intrusion. An accelerometer was installed at the top end of the vertical central axis of the model, with the purpose of measuring the time- 
history of the structure's acceleration. The accelerometer was capable of recording the acceleration in two directions: along and perpendicular to the direction of flow. At the same time, the displacement of the square model was recorded by a linear variable differential transformer LVDT with maximum displacement recording capacity of $50 \mathrm{~mm}$.

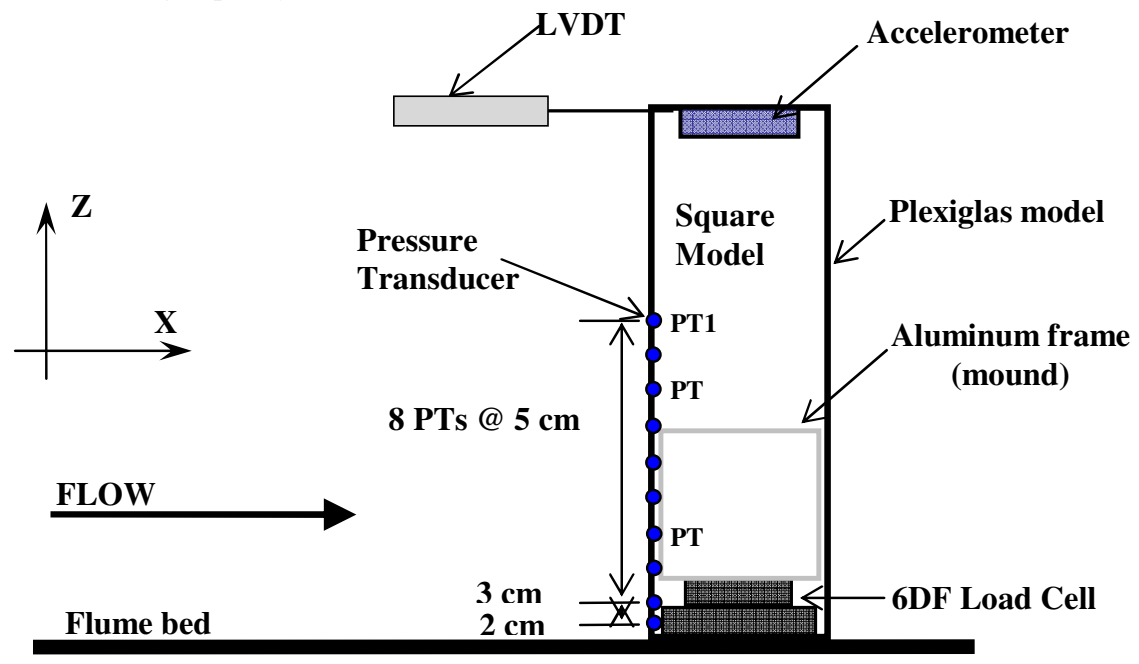

Figure 7. Instrumentation schema for the square structure.

\section{RESULTS AND DISCUSSION}

\section{Circular column}

The time history of the total global force induced by hydraulic bores generated through reservoir (impoundment) depths, h0, of 0.5, 0.75, 0.85 and $1.00 \mathrm{~m}$ was analyzed (Fig. 8).
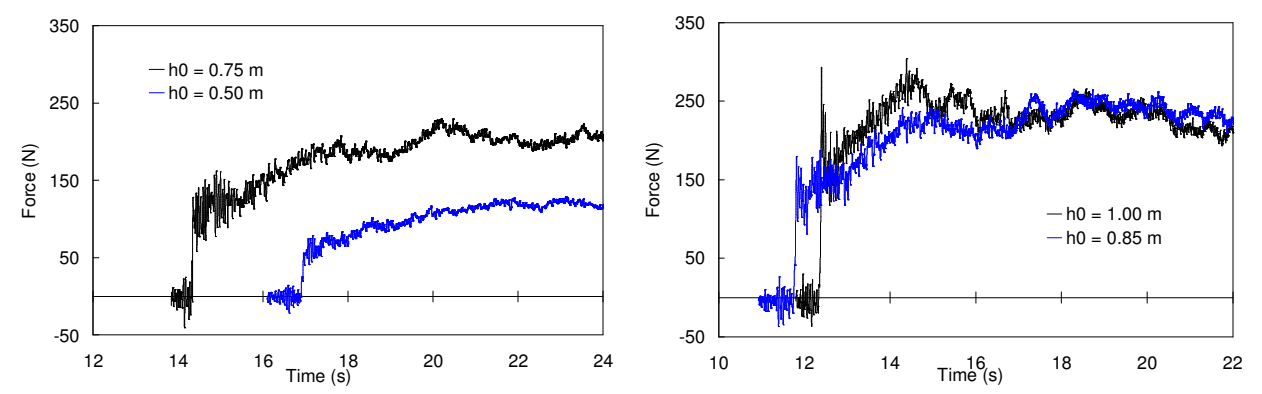

Figure 8. Time history of the total force exerted on the circular structure for various impoundment depths, h0, (Nouri, 2008).

Some oscillations can be observed in the recorded time history of the total force, prior to the bore impact. These oscillations occurred due to the natural vibration of the flume's bottom plate, which was not rigidly attached to the underlying beams.

The first sudden rise in the total force is due to the initial impact (surge force) of the hydraulic bore on the structure. With increasing impoundment depth, the surge force increased. This increase was partly due to the larger impoundment depth and the increase in bore front slope with increasing impoundment depth. Immediately following the initial impact, there was a drop in the base shear. For the $0.75 \mathrm{~m} .0 .85 \mathrm{~m}$, and $1.0 \mathrm{~m}$ impoundment depths, the reduction in force ranged between $55-60 \%$ of the initial impacting force. For the $0.50 \mathrm{~m}$ impoundment depth, the drop was approximately $30 \%$ of the initial force. The drop in force was followed by a gradual increase caused by the run-up of the hydraulic bore. In all cases, the run-up force was equal to or greater than the initial impacting load. The run-up was pursued by a semi-steady state of flow leading to the drag force. Excluding the $1.0 \mathrm{~m}$ impoundment depth, the drag force represented the largest force component in the loading history. 
Figure 9 shows the time history of the bore height (water elevation) on the front of the circular column and the time history of the total base shear force recorded by the load cell on which the circular structure was mounted.

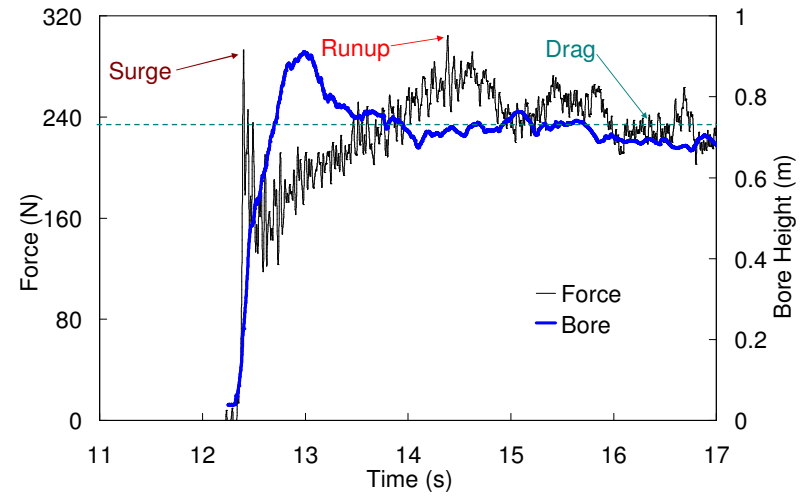

Figure 9. Time history of total force exerted on the circular structure (impoundment depth of $1.0 \mathrm{~m}$ )

Fig. 10 provides the time-history of the pressure variation for the circular section, recorded by the pressure transducers located along its vertical face, facing the incoming bore (measurements correspond to an impoundment water depth of $1.0 \mathrm{~m}$ ).

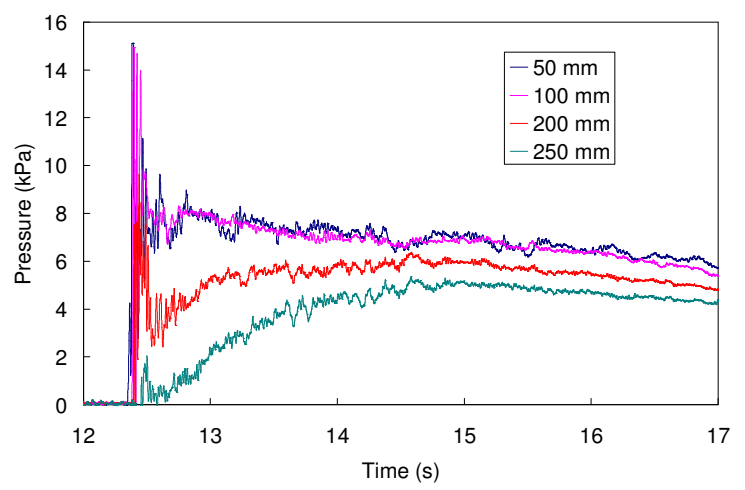

Figure 10. Time history of pressures on the circular column (impoundment depth of $1.0 \mathrm{~m}$ )

Fig. 11 provides the pressure distribution corresponding to the individual force components. As expected, distribution of the vertical pressure recordings was significantly different from the hydrostatical pressure for the equivalent water depth. It can be observed that, for the $1 \mathrm{~m}$ impoundment depth on the circular section, the maximum pressure occurred at $40 \%$ of the height of the bore from the base of the structure. The run-up and drag forces induced pressures up to $550 \mathrm{~mm}$. Relative to the surge force these forces are slightly more constant over the height.

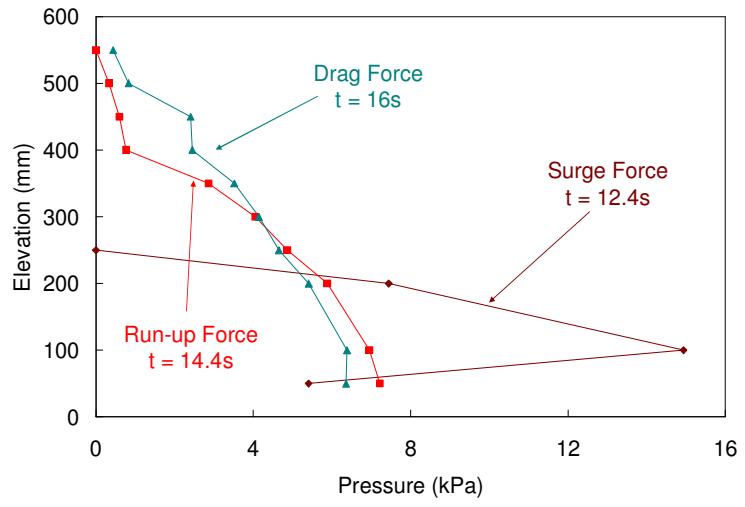

Figure 11. Vertical pressure distribution corresponding to hydrodynamic forces 
Square column (preliminary)

Results of the tests on the square column are shown in Fig. 12 shows the time history of the pressures and bore height on the front face of the square column following bore generated by an impoundment depth of $0.55 \mathrm{~m}$. The six degrees of freedom load cell had a sampling rate of $1 \mathrm{kHz}$. Each test was repeated for at least three times to verify the consistency of the recorded data. Data recording for all sensors were collected as time series which were further statically analyzed to find the maximum, minimum, average and standard deviation of the data collected.

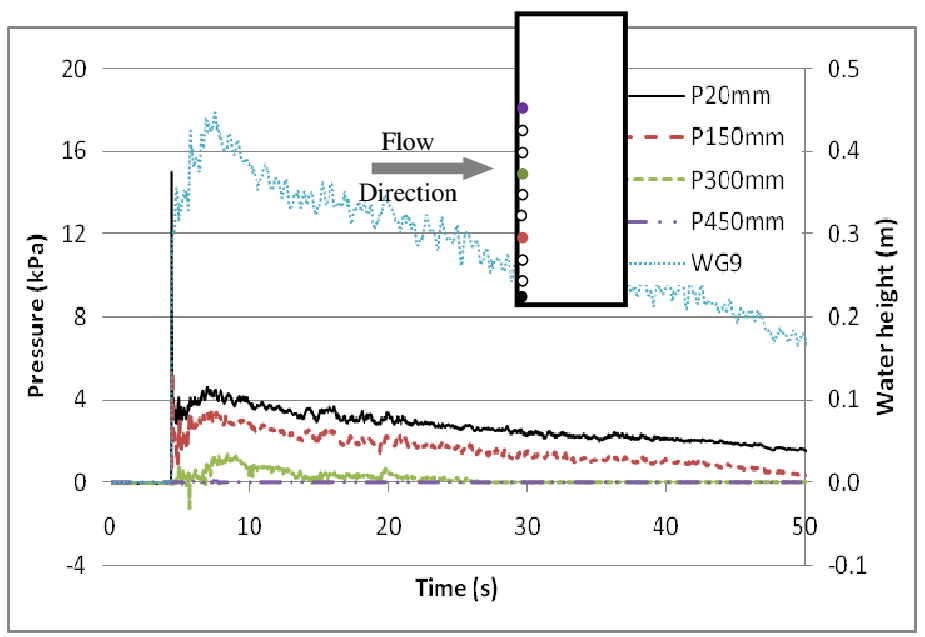

Figure 12. Time history of pressures and bore height on the front face of the square column (impoundment depth of $0.55 \mathrm{~m}$ )

Figure 13 shows the time history of the base shear forces $F_{x}$ and $F_{y}$ as well as the bore height on the front face of the square column for an impoundment depth of $0.55 \mathrm{~m}$. The positive sign of force $\mathrm{F}_{\mathrm{x}}$ refers to with flow direction and the same system of coordinates was applied to the displacement data.

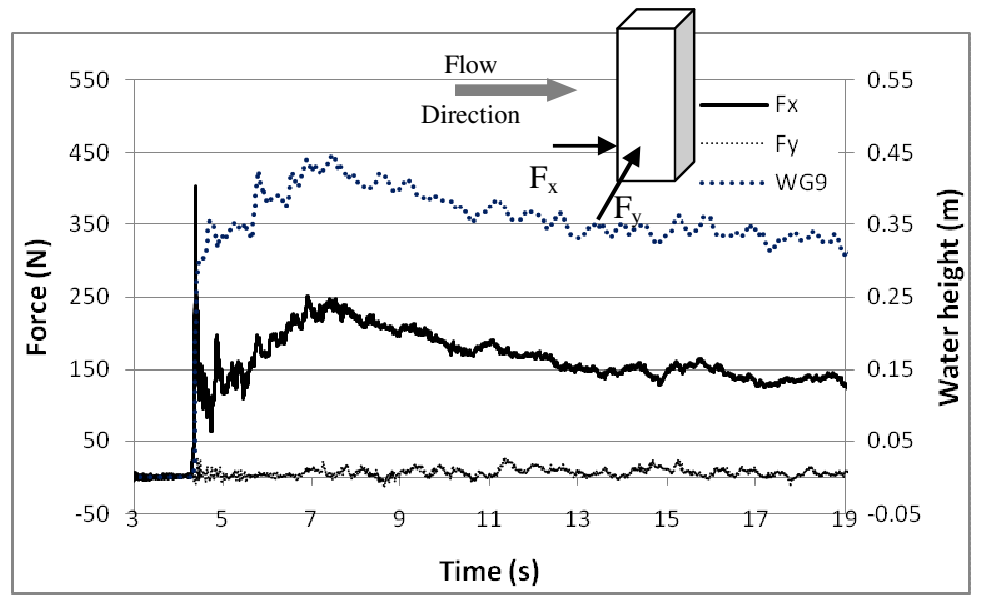

Figure 13. Time history of base shear forces and bore height on the front face of the square column (impoundment depth of $0.55 \mathrm{~m}$ )

An important observation is related to the recorded time history of the magnitude of the transversal base shear force, $\mathrm{F}_{\mathrm{y}}$, which demonstrates that the effect of the lateral confinement of the flume walls is indeed, as observed during the video recordings and testing, negligible. For the preliminary tests, one can observe the presence of a significant impulsive force recorded at the initial impact of the bore with the structure. Further tests are underway to observe the time history of forces, pressures, accelerations and displacements for this structure. 


\section{NUMERICAL MODELLING OF THE HYDRODYNAMIC FORCES USING THE SHP METHOD}

The numerical modeling of the large-scale experimental work using a three-dimensional Smoothed Particle Hydrodynamics (SPH) numerical model is another component of this project.

SPH is a mesh-free, (Lagrangian) particle method that was first introduced in the late seventies for simulating astrophysical problems (Lucy 1977, Gingold and Monaghan 1977). In this method, a set of irregularly spaced particles is used to represent the moving fluid and each of these particles has associated properties, such as mass, density, velocity, pressure, energy, etc. For a given time step, the properties of each particle are approximated according to the corresponding properties of the neighboring particles situated within an influence domain. Since the formulation of SPH is not affected by the arbitrariness of the particle distribution, the method can handle problems with extremely large deformation without any surface treatment, and this is considered to be the most attractive features of the method. Among numerous other applications, the method was successfully used by Gomez-Gesteira and Dalrymple (2004) for simulating wave impacts on structures. In their work, they reproduced a small-scale experiment performed by Yeh and Petroff at the University of Washington referred to as a "bore in a box", where a dam-break wave impacted a free-standing rectangular structure. The goal of this stage of the project is to provide further validation of the SPH model for the case of the experimental modeled interaction between a large-scale hydraulic bore and a slender structure.

The authors have further modified the SPHysics model of Gersteira et al. (2009), which is based on the Smooth Particle Hydrodynamics method, to numerically model their own experimental runs. Several modifications were performed in order to account for the different geometry (round shapes), boundary conditions, geometry. Some of the parameters of the numerical model that were used in the present simulation are: (1) the repulsive boundary condition; (2) laminar viscosity with Sub-Particle Scale (SPS) turbulence formulation proposed by Dalrymple and Rogers (2006) was used to describe the viscous terms of the momentum equation; (3) quadratic smoothing kernel introduced by Johnson et al. (1996); (4) the symplectic algorithm is used for advancing time; (5) the non-conservative Riemann solver proposed by Parshikov et al. (2000) was employed.

For the results shown herein (impact on the circular column), the computational domain included 319,000 particles, the time step used was $\mathrm{t}=0.001 \mathrm{~s}$ distance between particles was $0.035 \mathrm{~m}$ and the smoothing length was of $0.515 \mathrm{~m}$. The total computational time for duration of simulation of 4.00 seconds was approximately 172 hours (using a $2 \mathrm{GHz}$ Intel Xeon E5405 system with single processor and $16 \mathrm{~Gb}$ RAM). Figure 14 presents results of the flow velocity field around the circular structure for an initial upstream impoundment depth of 0.75 meter.

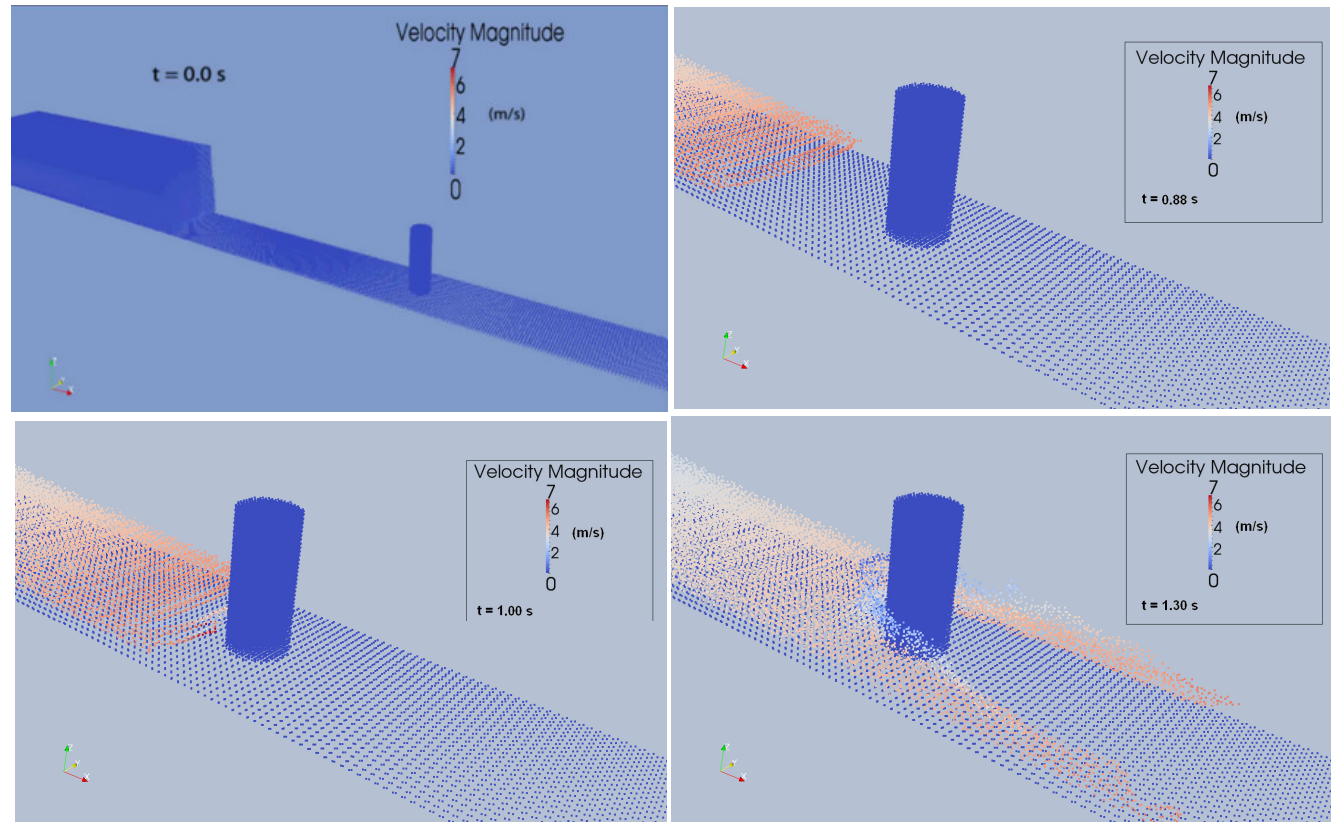

Figure 14. Flow velocity field around the circular column at $t=0.00,0.88,1.00$, and 1.33 seconds after gate opening. 
Figure 15 presents results of the pressure field around the circular structure for an initial upstream impoundment depth of 0.75 meter.
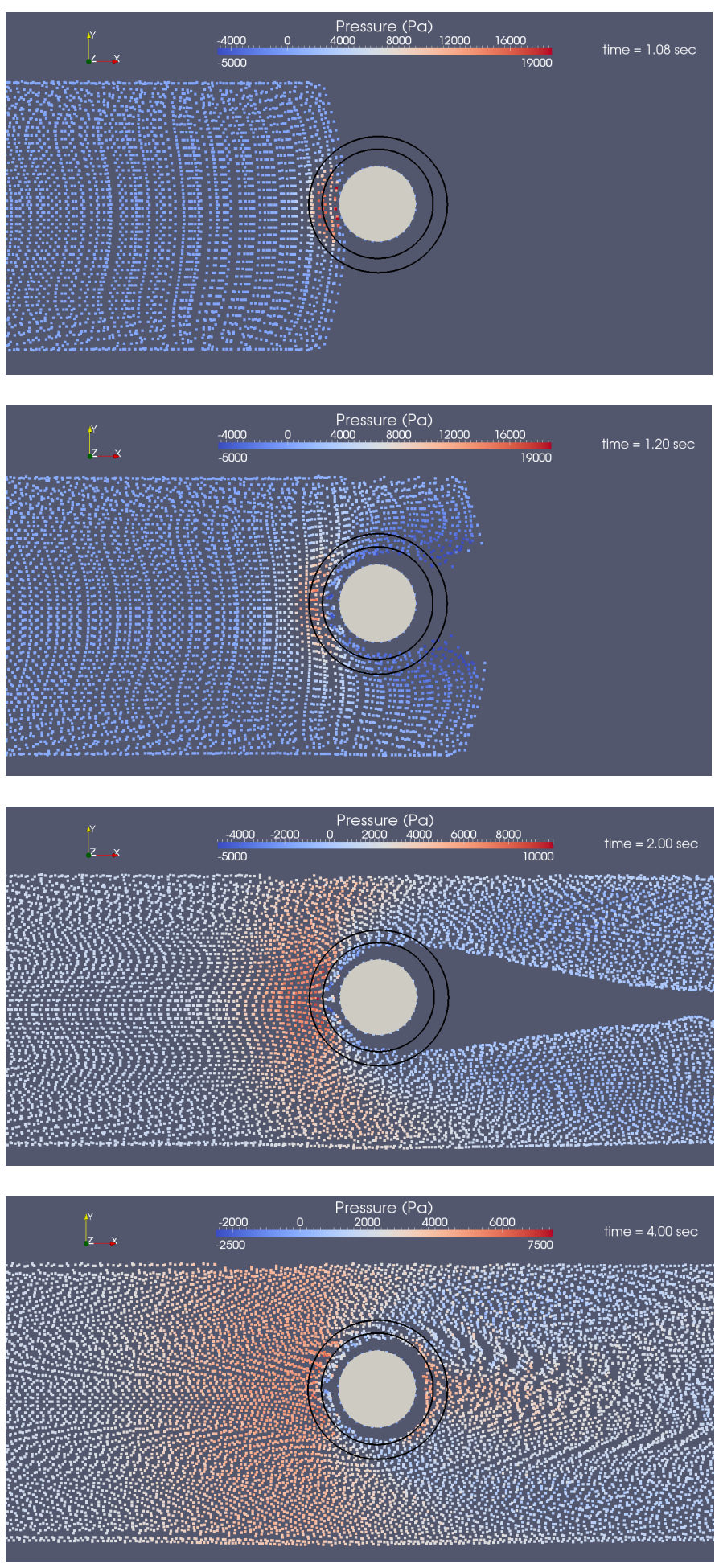

Figure 15. Pressure field around the circular column after gate opening. 
Figure 16 presents preliminary results of the comparison between numerical and experimental pressure time histories for three different elevations (pressure transducers) on the front face of the circular column for tests carried out on the circular column with an impoundment depth of $0.75 \mathrm{~m}$.
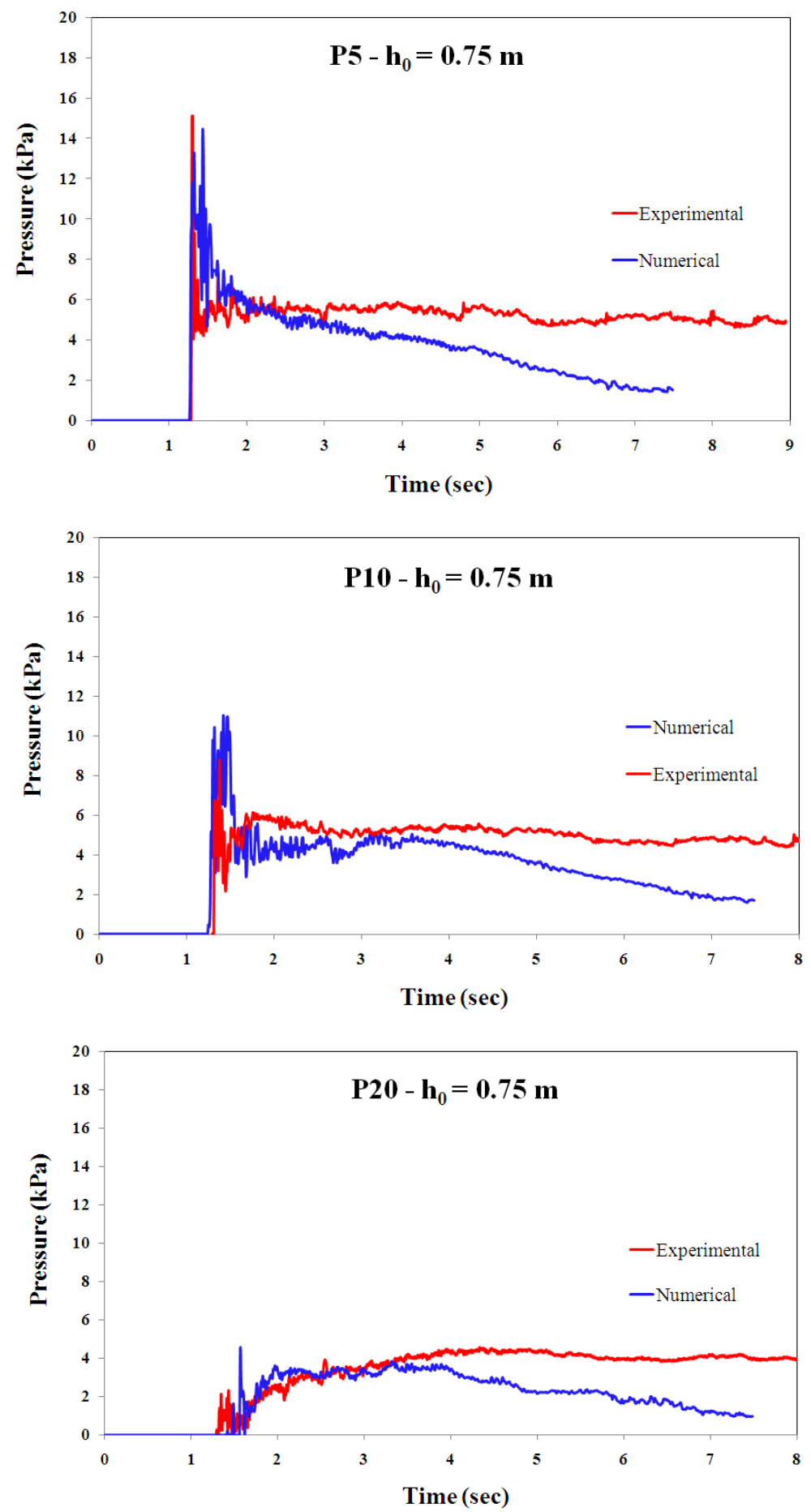

Figure 16. Comparison of the experimental and numerical pressure time-history for various pressure transducers (circular column with impoundment of $0.75 \mathrm{~m}, \mathrm{~h}_{0}$ represents the bottom of the flume) 
The present numerical model is shown to reproduce reasonably the results of the experimental work. However, work is under way in order to modify and improve the current SPH model and the method used to integrate the computed pressure distributions.

\section{CONCLUSIONS}

An experimental, analytical, and numerical modeling research program, which is still in progress, has been undertaken with the purpose of providing a better understanding of the physical mechanisms of the interaction between the tsunami-induced hydrodynamic forces and structures located in tsunami risk areas. The paper attempts to provide a quantitative and qualitative estimation of the time-history pressures, the flow field velocities, and the distribution of hydrodynamic forces on structures exerted by a rapidly advancing hydraulic bore, similar to the tsunami-induced coastal flooding. The results of this comprehensive research program which includes field investigations, as well as experimental, analytical and numerical models will be hopefully used to develop design guidelines which would directly address tsunami loading for structure design and constructed in tsunami-prone areas.

\section{ACKNOWLEDGMENTS}

The authors would like to thank the Canadian Hydraulic Center of the National Research Council in Ottawa, Canada, for providing access to their experimental facilities and for facilitating the work on the experimental tests. The authors are also grateful to the Natural Sciences and Engineering Council (NSERC) Canada for providing financial support for this study.

\section{REFERENCES}

Chanson, H. 2005. Analytical solution of dam-break wave with flow resistance: Application to tsunami surges, Proceedings 31st Biennial IAHR Congress, Seoul, Korea, 0137, 3341-3353.

Chanson, H. 2006. Tsunami surges on dry coastal plains: Application of dam break wave equations, Coastal Engineering Journal, JSCE, 48(4), 355-370.

Dalrymple, R. A., and B. D. Rogers. 2006. Numerical modeling of water waves with the SPH method, Coastal Engineering, 53(2-3), 141-147.

FEMA 55. 2000. Coastal Construction Manual, Federal Emergency Management Agency, Washington, D.C., USA.

FEMA P646. 2008. Guidelines for Design of Structures for Vertical Evacuation from Tsunamis, Federal Emergency Management Agency, Washington, D.C., USA.

Gingold, R. A. and Monaghan, J. J. 1977. Smoothed particle hydrodynamics: theory and application to non-spherical stars, Monthly Notices of the Royal Astronomical Society, 181, 375-389.

Gomez-Gesteira, M., and R.A. Dalrymple. 2004. Using a 3D SPH Method for Wave Impact on a Tall Structure, J. Waterways, Port, Coastal, Ocean Engineering, ASCE, 130(2), 63-69.

Gomez-Gesteira, G., B.D. Rogers, R.A. Dalrymple, A.J.C. Crespo, and M. Narayanaswamy 2009. User Guide for the SPHysics code, $73 \mathrm{p}$.

Ghobarah, A., M. Saatcioglu, and I. Nistor. 2006. The impact of 26 December 2004 earthquake and tsunami on structures and infrastructure, Engineering Structures, Elsevier, 28, 312-326.

Johnson, G. R., R.A. Stryk, and S.R. Beissel. 1996. SPH for high velocity impact computations, Computer Methods in Applied Mechanics and Engineering, 139(1-4), 347-373.

Lucy, L. B. 1977. A numerical approach to the testing of the fission hypothesis, The Astronomical Journal, 82(12), 1013-1024.

Nirupama, N., K. Ponnambalam, I. Nistor, and T. Murty. 2007. Tsunami Travel Time Atlas for the Atlantic Ocean, York University Printing Services, Toronto, 165 p.

Nistor, I., M. Saatcioglu and A. Ghobarah. 2005. The 26 December 2004 Earthquake and Tsunami Hydrodynamic forces on physical infrastructure in Thailand and Indonesia, Proceedings 2005 Canadian Coastal Engineering Conference., Halifax, Canada, CD-ROM, 15pp.

Nistor, I., D. Palermo, Y. Nouri, T. Murty, and M. Saatcioglu. 2009. Tsunami forces on structures, Chapter 11, Handbook of Coastal and Ocean Engineering, World Scientific, 261-286.

Nouri, Y., I. Nistor, D. Palermo, and A. Cornett. 2010. Experimental investigation of the tsunami impact on free standing structures, Coastal Engineering Journal, JSCE, 52 (1), 43-70.

Nouri, Y. 2008. The Impact of Hydraulic Bores and Debris on Free Standing Structures, M.A.Sc. Thesis, Department of Civil Engineering, University of Ottawa, Canada, 136 pp.

Okada, T., T. Sugano, T. Ishikawa, T. Ohgi, S. Takai, and C. Hamabe. 2005. Structural design methods of buildings for tsunami resistance, (SMBTR), the Building Centre of Japan. 
Palermo, D., I. Nistor, Y. Nouri, and A. Cornett. 2009. Tsunami loading of nearshore structures: a premier, Canadian Journal of Civil Engineering, NRC, 1804-1815.

Parshikov, A. N. 1999. Application of a solution of the Riemann problem to the SPH method, Computational Mathematics and Mathematical Physics, 39, 1173.

Saatcioglu, M., Ghobarah, A., Nistor, I., 2006. Performance of structures in Indonesia during the 2004 Sumatra earthquake and tsunami, Earthquake Spectra, Earthquake Engineering Research Institute, ASCE, 22(S3), 295-320.

Tomita, T., F. Imamura, T. Arikawa, T. Yasuda, and Y. Kawata. 2006. Damage caused by the 2004 Indian Ocean Tsunami on the south-western coast of Sri Lanka, Coastal Engineering Journal, JSCE, 48(2), 99-116.

Yamamoto, Y., H. Takanashi, S. Hettiarachchi, and S. Samarawickrama. 2006. Verification of the destruction mechanism of structures in Sri Lanka and Thailand due to the Indian Ocean tsunami, Coastal Engineering Journal, JSCE, 48(2), 117-146.

Yeh, H., and K. M. Mok. 1990. On turbulence in bores, Phys. Fluids, A2, 821-828.

Yeh, H. 1991. Tsunami bore runup, Natural Hazards, 4, 209-220.

Yeh, H., I. Robertson, and J. Preuss. 2005. Development of design guidelines for structures that serve as tsunami vertical evacuation sites, Report No 2005-4, Washington Dept. of Natural Resources. 